\title{
Prevalence of diabetes and pre-diabetes in rural Tehri Garhwal, India: influence of diagnostic method
}

\author{
Pam Anderson ${ }^{1}$, Nathan Grills ${ }^{1}$, Rajesh Singh², Rajkumari Singh ${ }^{2}$, Roger G. Evans ${ }^{3}$, Paramita Sengupta ${ }^{4}$ and \\ Amanda G. Thrift ${ }^{5^{*}}$ (D)
}

\begin{abstract}
Background: There are few available data regarding the prevalence of diabetes in the sub-Himalayan region of India. The aim of this study was to determine the prevalence of pre-diabetes and diabetes in rural Garhwal based on glycosylated hemoglobin.

Methods: In a cross-sectional survey of 500 adults from five randomly selected villages in Chamba, a mountainous Tehri Garhwal district in Uttarakhand in north-west India, we determined the prevalence of diabetes (hemoglobin $\left.(\mathrm{Hb}) \mathrm{A}_{1 \mathrm{c}} \geq 6.5 \%\right)$ and pre-diabetes $\left(5.7 \% \leq \mathrm{HbA}_{1 c} \leq 6.4 \%\right)$. In a sub-sample of those diagnosed with diabetes or prediabetes $(n=140)$, fasting blood glucose (FBG, $n=117$ ) or postprandial blood glucose (PBG, $n=23$ ), and blood hemoglobin concentration, was measured at follow-up.

Results: Based on $\mathrm{HbA}_{1 c}, 10.0 \%$ had diabetes and $56.4 \%$ pre-diabetes. Of those diagnosed as diabetic by $\mathrm{HbA}_{1 c}, 10$ of 16 (62.5\%) were diagnosed as diabetic by FBG (>125 mg/dL) or PBG ( $\geq 200 \mathrm{mg} / \mathrm{dL})$. In those diagnosed as pre-diabetic by $\mathrm{HbA}_{1,}$, only 55 of 124 (44.4\%) were diagnosed as pre-diabetic by FBG (100-125 mg/dL) or PBG (140-199 mg/dL). A large proportion of these 140 individuals (67.1\%) were moderately to severely anemic ( $\mathrm{Hb}<11.4 \mathrm{mg} / \mathrm{dL})$. The diagnostic gap for pre-diabetes between $\mathrm{HbA}_{1 c}$ and $\mathrm{FBG} / \mathrm{PBG}$ was similar for the groups with and without moderate to severe anemia.

Conclusions: $\mathrm{HbA}_{1 c}$ and $\mathrm{FBG} / \mathrm{PBG}$ have similar diagnostic performance for diabetes in this population. However, many individuals were diagnosed with pre-diabetes by $\mathrm{HbA}_{1 c}$ but not FBG/PBG. The relative excess diagnosis of pre-diabetes with $\mathrm{HbA}_{1 \mathrm{c}}$ does not appear to be explained by anemia, an endemic condition in India. The prognostic significance of diagnosis of pre-diabetes by $\mathrm{HbA}_{1 \mathrm{c}}$ but not FBG/PBG remains unknown, but merits investigation.
\end{abstract}

Keywords: Anemia, Diabetes, Disadvantage, Fasting blood glucose, Glycosylated hemoglobin

\section{Introduction}

Worldwide, diabetes is a major contributor to morbidity and mortality [1]. In India the prevalence of diabetes and pre-diabetes is a growing public health concern. There are more than 69 million people with diabetes and this is estimated to increase to 80 million individuals by 2030 [2]. Despite the large number of people with diabetes there are few data about this condition in rural north India [3]. Most available data regarding the

\footnotetext{
* Correspondence: amanda.thrift@monash.edu

${ }^{5}$ Department of Medicine, School of Clinical Sciences at Monash Health,

Monash University, Clayton, Victoria 3800, Australia

Full list of author information is available at the end of the article
}

prevalence of diabetes in India come from populations in urban or southern regions [4-8]. But little is known about the mountainous regions of the north where poverty and poor access to health care facilities may exacerbate the problem.

Another factor that hampers studies of the prevalence of type 2 diabetes is the diagnostic methods available. The main diagnostic tests for diabetes include (1) fasting blood glucose; (2) random blood glucose; (3) glycosylated hemoglobin $\left(\mathrm{HbA}_{1 \mathrm{c}}\right)$; and (4) the oral glucose tolerance test (OGTT). Each test has benefits and disadvantages. $\mathrm{HbA}_{1 \mathrm{c}}$ is now widely accepted for diagnosis $[9,10]$, providing a measure of glycemic control over

(c) The Author(s). 2019 Open Access This article is distributed under the terms of the Creative Commons Attribution 4.0 International License (http://creativecommons.org/licenses/by/4.0/), which permits unrestricted use, distribution, and reproduction in any medium, provided you give appropriate credit to the original author(s) and the source, provide a link to the Creative Commons license, and indicate if changes were made. The Creative Commons Public Domain Dedication waiver (http://creativecommons.org/publicdomain/zero/1.0/) applies to the data made available in this article, unless otherwise stated. 
the prior 3 months $[11,12]$, but is relatively expensive and has limited availability in some middle to low income countries [9]. While random blood glucose is more affordable and convenient as it requires no fasting, it is not recommended as a single diagnostic test unless classic symptoms of diabetes are present [9]. Fasting blood glucose and OGTT have been widely used as the standard diagnostic methods [13]. However, both tests have their limitations. The FBG test requires fasting, hence it can be problematic in an outpatient setting whereas OGTT is relatively expensive and has low reproducibility [13]. In reality, a mix of these screening tests are used in the diagnosis of diabetes in regions such as rural North India. It is unclear whether there are differences in the prevalence of diabetes in such settings according to the diagnostic test used.

$\mathrm{HbA}_{1 \mathrm{c}}$ is rapidly becoming the test of choice. The American Diabetes Association has recommended that $\mathrm{HbA}_{1 \mathrm{c}}$ may be used as a substitute to fasting blood glucose for diagnosing diabetes [9]. As the costs come down and the availability increases in India it is anticipated that these tests will become more widely used. Yet, in the context of North India, it is unknown how this test might perform. There is some evidence that anemia, and in particular consumptive anemias, may affect the $\mathrm{HbA}_{1 \mathrm{c}}$ result [14]. In particular, iron deficiency anemias may result in a spurious increase in $\mathrm{HbA}_{1 \mathrm{c}}$ [15], leading to a potential over-estimate of the prevalence of diabetes and pre-diabetes. Given that the proportion of people with anemia can approach $50 \%$ in this area [16], it is critical to determine whether anemia might affect $\mathrm{HbA}_{1 \mathrm{c}}$ in these mountainous regions in north-west India.

We aimed to determine the prevalence of pre-diabetes and diabetes in rural Garhwal based on glycosylated hemoglobin. Our primary hypothesis was that diabetes and pre-diabetes are highly prevalent in the region. Based on our initial finding of relatively high prevalence of both diabetes and pre-diabetes, we then aimed to test the hypothesis that $\mathrm{HbA}_{1 \mathrm{c}}$ over-diagnoses diabetes and pre-diabetes when compared to FBG. In addition, considering the presence of endemic anemia in India [17] and the possible confounding effect of anemia on $\mathrm{HbA}_{1 \mathrm{c}}$ as a diagnostic marker of diabetes [14], we also aimed to determine whether anemia is associated with overdiagnosis of pre-diabetes and diabetes.

\section{Methods}

\section{Study design}

We randomly selected five villages from 58 villages located on the west side of Chamba, in the mountainous Tehri District in the Garhwal region of the state of Uttarakhand in northern India (May to July 2015), using random number generation. We undertook a cross- sectional survey of adults in each village for between 8 and 10 days, with the aim of obtaining approximately 100 participants per village. As we did not have a census for each village, randomization of individual participants was not possible. Health staff, including a nurse and health workers, recruited participants following full informed consent. Ethical approval was obtained from the Garhwal Community Development and Welfare Society, and written informed consent was obtained before any data were collected from each participant.

\section{Initial survey (time 1)}

We trained Accredited Social Health Activists (ASHAs), health-workers who reside in most villages in rural India, to administer a questionnaire and to conduct all the clinical and biochemical tests for this study. The ASHAs used questionnaire-based assessments to obtain details on age, sex, education, and monthly per-capita household income. ASHAs also measured height (Seca, Germany), weight (Salter, UK), and waist and hip circumference (Gulick, Patterson Medical, USA). Screening for diabetes and pre-diabetes was undertaken in 499 participants, using $\mathrm{HbA}_{1 \mathrm{c}}$ measured by the Afinion Analyzer (Alere, Oslo; Fig. 1). Staff from Chamba Hospital and a trained nurse were in the field to ensure clinical markers were properly measured.

\section{Follow-up (time 2)}

Approximately 3 months after the initial survey, a subset of individuals with diabetes or pre-diabetes were followed up with tests of fasting blood glucose and/or post-prandial blood glucose, and blood hemoglobin concentration (Fig. 1). As our aim was to provide management for people with diabetes and pre-diabetes, we aimed to follow-up only those with an $\mathrm{HbA}_{1 \mathrm{c}} \geq 5.7 \%$ at the initial visit. The FBG test was conducted after fasting 8 to $10 \mathrm{~h}$ and the PBG was taken $2 \mathrm{~h}$ after a meal $(75 \mathrm{~g}$ of glucose powder). Both FBG and PBG were assessed using an AccuSure glucometer (MicroGene, New Delhi). Using the same finger-prick blood samples for measuring FBG, blood hemoglobin concentration was assessed with a hemoglobinometer (Sahli's type) by staff from Chamba Hospital.

\section{Clinical definitions}

Diabetes and pre-diabetes were defined according to the American Diabetes Association's cut points [9]. Participants with $5.7 \% \leq \mathrm{HbA}_{1 \mathrm{c}} \leq 6.4 \%$ were classified as prediabetic and those with $\mathrm{HbA}_{1 \mathrm{c}} \geq 6.5 \%$ were classified as diabetic. Pre-diabetes was also defined as $100 \mathrm{mg} / \mathrm{dL} \leq$ $\mathrm{FBG} \leq 125 \mathrm{mg} / \mathrm{dL}$ or $140 \mathrm{mg} / \mathrm{dL} \leq \mathrm{PBG} \leq 200 \mathrm{mg} / \mathrm{dL}$. Diabetes was defined as a FBG $>125 \mathrm{mg} / \mathrm{dL}$ or PBG $>200$ $\mathrm{mg} / \mathrm{dL}$. Levels of $\mathrm{HbA}_{1 \mathrm{c}}$ and FBG were recoded into normal, pre-diabetes and diabetes based on these 


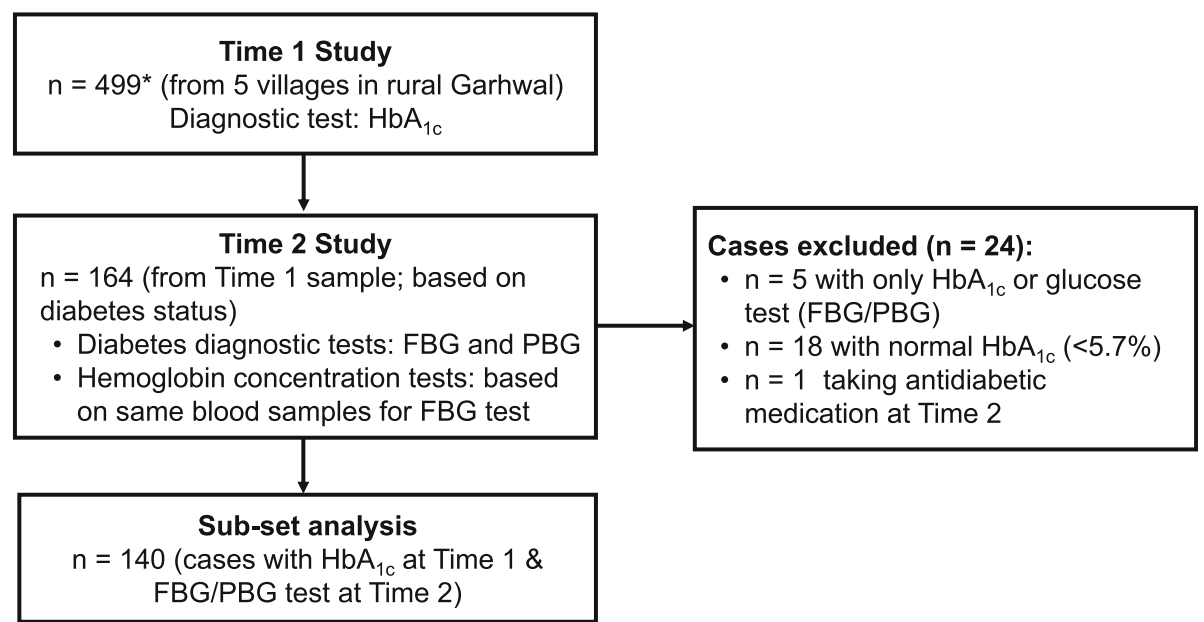

Fig. 1 Study Flow Diagram. ${ }^{*} \mathrm{HbA}_{1 c}$ at Time 1 was missing for 1 case, Average interval between Time 1 and Time $2=100$ days, $\mathrm{HbA}_{1 c}$ : Glycosylated hemoglobin, FBG: Fasting blood glucose, PBG: Post-prandial blood glucose

definitions. Moderate to severe anemia was defined as hemoglobin $<11.4 \mathrm{mg} / \mathrm{dL}$ adjusted for high altitude according to the World Health Organization's criteria [18]. Hemoglobin concentration levels above the cut-off were classified as normal to mild anemia.

\section{Statistical analysis}

All analyses were conducted using Stata version 14 (StataCorp., Texas). Age, weight, height, waist, hip, body mass index (BMI) and monthly income per capita (household monthly income/household size) are presented as medians and quartiles (Q1, Q3). Categorical variables (sex and education) are presented in percentages.

We assessed the crude prevalence of pre-diabetes and diabetes among the participants using $\mathrm{HbA}_{1 \mathrm{c}}$ measured during the initial survey (time 1). Age and gender specific prevalence of diabetes were compared using Pearson's Chi-square test. Similarly, we compared age specific percentages of diabetes and pre-diabetes based on the FBG and/or PBG obtained in time 2 using Pearson's Chi-square test.

The high prevalence of pre-diabetes at the initial survey prompted us to consider that anemia may have contributed to this surprising finding. To test whether $\mathrm{HbA}_{1 \mathrm{c}}$ over-diagnoses pre-diabetes and diabetes, we compared the proportions of the two conditions at time 1 with those determined by glucose tests taken at time 2 (August - October 2015) using McNemar's Chi-square test. In the majority of cases, FBG was used $(n=117$, $84 \%)$, but in those instances where this was unavailable $(n=23,16 \%)$, PBG was used. We excluded one case who began treatment for diabetes between time 1 and time 2 (Fig. 1).

To further understand the influence of hemoglobin concentration on the level of $\mathrm{HbA}_{1 \mathrm{c}}$, we used McNemar's test to compare the proportions of diabetes and pre-diabetes based on $\mathrm{HbA}_{1 \mathrm{c}}$ and glucose-based tests.

\section{Results \\ Baseline characteristics}

Of the 500 participants, 61\% (303) were female and 39\% (197) male. The median age of all participants was 50 years (IQR 42-60 years). More than half of the participants $(61.4 \%)$ had no formal schooling or no more than 6 years of education. The median monthly income per capita was 1000 rupees (500-3000 rupees, $n=400$ due to missing values for the number of people in the household). One person had missing information on $\mathrm{HbA}_{1 \mathrm{c}}$ (Fig. 1). There was a similar number of people recruited to each village (Additional file 1: Table S1).

There were notable differences in most of the anthropometric measures between individuals who were non-diabetic and those who were either pre-diabetic or diabetic according to $\mathrm{HbA}_{1 \mathrm{c}}$. Kruskal Wallis tests (set at 0.05 significance level) show that those with pre-diabetes or diabetes were progressively heavier, with greater BMI, waist and hip circumference, and waist-hip ratio (Additional file 2: Table S2).

\section{Prevalence of diabetes in rural Garhwal}

Based on $\mathrm{HbA}_{1 \mathrm{c}}$, the overall prevalence of diabetes was 10\% (95\% CI 7.6-13\%) and pre-diabetes 56.4\% (95\% CI $52-60.7 \%)$. Prevalence of pre-diabetes and diabetes was lowest in the youngest age group (Table 1).

There was a strong association between diabetes status and age $\left(\chi^{2}=13.3 ; p=0.01\right)$, but we were unable to detect a statistically significant association between gender and prevalence of pre-diabetes or diabetes $\left(\chi^{2}=1.07 ; p=0.59\right)$. 
Table 1 Diabetes status based on $\mathrm{HbA}_{1 c}$ at Time 1, according to age group

\begin{tabular}{llll}
\hline Age group & \multicolumn{3}{l}{ Prevalence $(95 \% \mathrm{Cl})$} \\
\cline { 2 - 4 } & Normal $^{\mathrm{a}}$ & Pre-diabetes $^{\mathrm{b}}$ & Diabetes $^{\mathrm{c}}$ \\
\hline 0-44 years & $44.3(36.7$ to 52.2$)$ & $48.7(41.0$ to 56.6$)$ & $7.0(3.9$ to 12.2) \\
45-59 years & $29.8(23.8$ to 36.4$)$ & $58.0(51.1$ to 64.7) & $12.2(8.3$ to 17.5) \\
$\geq$ 60 years & $27.2(20.3$ to 35.4$)$ & $63.2(54.7$ to 70.9$)$ & $9.6(5.6$ to 15.9)
\end{tabular}

Values represent percentages of cases within each age group with $95 \%$ confidence intervals in parentheses; $n=499 ; \mathrm{HbA}_{1 \mathrm{c}}$ is missing for one case ${ }^{a}$ Normal was defined as $\mathrm{HbA}_{1 \mathrm{c}}<5.7 \%(n=168)$

${ }^{\mathrm{b}}$ Pre-diabetes was defined as $5.7 \% \leq \mathrm{HbA} 1 \mathrm{c} \leq 6.4 \%(n=282)$

'Diabetes was defined as $\mathrm{HbA} 1 \mathrm{c} \geq 6.5 \%(n=49)$

\section{Glycosylated hemoglobin vs fasting blood glucose/post- prandial blood glucose}

Among the 140 people we followed-up, we could detect no significant change in anthropometric variables between the times of measurement of $\mathrm{HbA}_{1 \mathrm{c}}$ and FBG/ PBG (Table 2). Of these 140 people, 124 (88.6\%) were pre-diabetic according to $\mathrm{HbA}_{1 \mathrm{c}}$ cut-offs compared to 56 (40.0\%) using FBG/PBG (Table 3). This corresponds to a $48.6 \%$ greater percentage of pre-diabetes using $\mathrm{HbA}_{1 \mathrm{c}}$ than by FBG/PBG (95\% CI: 39.3 to $57.7 \%$ ) (McNemar's chi-square $=66.1 ; p<0.001)$.

There was no evidence that diabetes was overdiagnosed when $\mathrm{HbA}_{1 \mathrm{c}}$ was used as the diagnostic criterion. The difference in proportions of diabetes assessed by $\mathrm{HbA}_{1 \mathrm{c}}$ and FBG/PBG was -0.02 (95\% CI: -0.07 to 0.05 ; McNemar's $X^{2}=0.29 ; p=0.79$ ).

\section{Hemoglobin, $\mathrm{HbA}_{1 \mathrm{c}}$ and fasting blood glucose}

In both people with and without moderate to severe anemia, a much smaller proportion were diagnosed with pre-diabetes by FBG/PBG than $\mathrm{HbA}_{1 \mathrm{c}}$ (Table 4). The difference between the two diagnostic criteria was consistent across the two categories of hemoglobin concentration [no anemia or mild anemia: $0.48(0.37-$ 0.61 ); McNemar's $x^{2}=44.1 ; p<0.01$; moderate to severe anemia: $0.48(0.31-0.64)$, McNemar's $\chi^{2}=22 ; p<$ 0.01]. Similarly, the proportions categorized by $\mathrm{HbA}_{1 \mathrm{c}}$ and FBG/PBG as diabetic did not differ markedly according to category of blood hemoglobin concentration (Table 4).

\section{Discussion}

The prevalence of both pre-diabetes and diabetes in our study sample was generally much higher than other states of India and other South Asian countries [4, 19]. We observed a large disparity between proportions of the sample diagnosed with pre-diabetes based on $\mathrm{HbA}_{1 \mathrm{c}}$ and FBG/PBG. However, we were unable to detect a difference in the proportions of diabetics diagnosed by the two tests. It has been suggested that anemia can influence $\mathrm{HbA}_{1 \mathrm{c}}$ levels, and thus the performance of this diagnostic test [14]. However, our data indicate that the diagnostic gap between pre-diabetes based on $\mathrm{HbA}_{1 \mathrm{c}}$ and FBG/PBG is unlikely to be attributable to confounding by the high prevalence of anemia in the population we studied.

Table 2 Age, anthropometric and biochemical characteristics of participants with $\mathrm{HbA}_{1 \mathrm{c}}$ and glucose-based test

\begin{tabular}{|c|c|c|c|}
\hline & Time $1^{a}$ & Time $2^{a}$ & $p$-value \\
\hline Age, years & $52(18)$ & NA & NA \\
\hline $\mathrm{HbA}_{1 \mathrm{c}}(\%)$ & $5.9(5.8-6.2)$ & NA & NA \\
\hline Height, cm & $154.5(149.5-161.3)^{\mathrm{b}}$ & As for Time 1 & NA \\
\hline Weight, kg & $56.0(48.8-64.0)^{b}$ & $55.0(46.6-63.4)$ & 0.06 \\
\hline Body mass index, $\mathrm{kg} / \mathrm{m}^{2}$ & $22.7(19.8-25.7)^{c}$ & $22.3(19.6-25.7)^{\mathrm{b}}$ & 0.08 \\
\hline Waist, $\mathrm{cm}$ & 80.7 (70.0-89.6) & $81.3(71.5-89.8)$ & 0.22 \\
\hline $\mathrm{Hip}, \mathrm{cm}$ & $93.0(88.2-97.8)$ & $92.8(88.0-97.5)$ & 0.24 \\
\hline Waist-hip ratio & $0.87(0.8-0.9)$ & $0.88(0.8-0.9)$ & 0.79 \\
\hline $\mathrm{FBG}, \mathrm{mg} / \mathrm{dL}$ & NA & $104(95-114)^{d}$ & NA \\
\hline $\mathrm{PBG}, \mathrm{mg} / \mathrm{dL}$ & NA & $130(111-152)^{e}$ & NA \\
\hline Hemoglobin, g/dL & NA & $11(10-12)$ & NA \\
\hline
\end{tabular}

Data show median of baseline characteristics with interquartile range in parentheses

$n=140$, excluding 18 subjects with normal $\mathrm{HbA}_{1 \mathrm{c}}$ results $\left(\mathrm{HbA}_{1 \mathrm{c}}<5.7 \%\right)$

$p$-values were based on Wilcoxon's signed-rank test

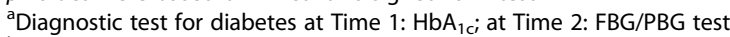

${ }^{\mathrm{b}}$ Time 1 Height \& Weight; Time 2 BMI: $n=139$

'Time 1 BMI: $n=138$

dime 2 FBG: $n=117$

e Time 2 PBG: $n=135$

$B M I$ body mass index, $H b A_{1 c}$ glycosylated hemoglobin, FBG fasting blood glucose, $P B G$ post-prandial blood glucose, NA not applicable/available 
Table 3 Diabetic status based on fasting blood glucose or postprandial glucose, among those diagnosed as pre-diabetic or diabetic using $\mathrm{HbA}_{1 \mathrm{c}}$

\begin{tabular}{llll}
\hline \multirow{2}{*}{$\begin{array}{l}\text { Diagnosis } \\
\text { based on } \\
\text { FBG/PBG }\end{array}$} & \multicolumn{4}{l}{ Diagnosis based on $\mathrm{HbA}_{1 \mathrm{c}}{ }^{\mathrm{a}}$} & \\
\cline { 2 - 4 } & Pre-diabetes & Diabetes & Total \\
\hline No Diabetes & $61(49.2 \%)$ & $5(31.2 \%)$ & 66 \\
Pre-diabetes & $55(44.4 \%)$ & $1(6.3 \%)$ & 56 \\
Diabetes & $8(6.5 \%)$ & $10(62.5 \%)$ & 18 \\
Total & $124(100 \%)$ & $16(100 \%)$ & 140 \\
\hline
\end{tabular}

Values are number of cases and column percentages

$H b A_{1 c}$ glycosylated hemoglobin, FBG fasting blood glucose, $P B G$ post-prandial blood glucose

${ }^{a}$ Tested at time 1; pre-diabetes was defined as $5.7 \% \leq \mathrm{HbA}_{1 \mathrm{c}} \leq 6.4 \%$; diabetes was defined as $\mathrm{HbA}_{1 \mathrm{c}} \geq 6.5 \%$

${ }^{\mathrm{b}}$ Tested at time 2; pre-diabetes was defined as $100 \mathrm{mg} / \mathrm{dL} \leq \mathrm{FBG} \leq 125 \mathrm{mg} / \mathrm{dL}$ or $140 \mathrm{mg} / \mathrm{dL} \leq \mathrm{PBG} \leq 200 \mathrm{mg} / \mathrm{dL}$; diabetes was defined as $\mathrm{FBG}>125 \mathrm{mg} / \mathrm{dL}$ or PBG $>200 \mathrm{mg} / \mathrm{dL}$

In the instances where FBG was not available, diagnosis was based on PBG

\section{Proportions of diabetes and pre-diabetes}

Our findings indicate that $\mathrm{HbA}_{1 \mathrm{c}}$ has comparable performance to FBG/PBG with regard to diagnosis of diabetes in this rural population. $\mathrm{HbA}_{1 \mathrm{c}}$ and glucose tests both detected very similar proportions of diabetes in the sample we studied. Our finding is consistent with those of two recent studies, one in an out-patient clinic in China and another in a tertiary care setting in India [20, 21]. However, substantial disparities between diagnoses based on $\mathrm{HbA}_{1 \mathrm{c}}$ and glucose-based tests have previously been reported [4, 22-26]. In some cases $\mathrm{HbA}_{1 \mathrm{c}}$ diagnosed much larger proportions of diabetes than did FBG $[4,23-25]$ while in other studies $\mathrm{HbA}_{1 \mathrm{c}}$ diagnosed smaller percentages of diabetes than did FBG [22, 26]. These studies varied in settings ranging from general communities as well as sea-level and high-altitude settings, covering various ethnic groups including Arabs, Asian-Americans, Native Hawaiians and Peruvians.

Table 4 Diabetic status based on glycosylated hemoglobin and glucose-based tests, according to anemia status

\begin{tabular}{|c|c|c|c|c|}
\hline & \multicolumn{2}{|c|}{$\begin{array}{l}\text { No/Mild Anemia }{ }^{a} \\
n=46\end{array}$} & \multicolumn{2}{|c|}{$\begin{array}{l}\text { Moderate/Severe Anemia } \\
n=94\end{array}$} \\
\hline & $\mathrm{HbA}_{1 c}{ }^{\mathrm{b}}$ & $\mathrm{FBG} / \mathrm{PBG}^{\mathrm{C}}$ & $\mathrm{HbA}_{1 c}{ }^{\mathrm{b}}$ & $\mathrm{FBG} / \mathrm{PBG}^{\mathrm{C}}$ \\
\hline No Diabetes & - & $21(45.7 \%)$ & - & 45 (47.9\%) \\
\hline Pre-diabetes & 39 (84.8\%) & 17 (37.0\%) & 85 (90.4\%) & 39 (41.5\%) \\
\hline Diabetes & 7 (15.2\%) & 8 (17.4\%) & 9 (9.6\%) & $10(10.6 \%)$ \\
\hline
\end{tabular}

Only cases with both $\mathrm{HbA}_{1 \mathrm{c}}$ at Time 1 and FBG/PBG at Time 2 were included in analysis; $n=140$, excluding 18 subjects with normal $\mathrm{HbA}_{1 \mathrm{c}}$ results $\left(\mathrm{HbA}_{1 c}<5.7 \%\right)$

${ }^{\mathrm{a}} \mathrm{No} / \mathrm{mild}$ anemia was defined as $\mathrm{Hb}>11.4 \mathrm{~g} / \mathrm{dL}$; moderate/severe anemia was defined as $\mathrm{Hb} \leq 11.4 \mathrm{~g} / \mathrm{dL}$

${ }^{\mathrm{b}}$ Pre-diabetes was defined as $5.7 \% \leq \mathrm{HbA} 1 \mathrm{c} \leq 6.4 \%$; diabetes was defined as $\mathrm{HbA} 1 \mathrm{c} \geq 6.5 \%$

'Pre-diabetes was defined as $100 \mathrm{mg} / \mathrm{dL} \leq \mathrm{FBG} \leq 125 \mathrm{mg} / \mathrm{dL}$ or $140 \mathrm{mg} / \mathrm{dL} \leq$ $\mathrm{PBG} \leq 200 \mathrm{mg} / \mathrm{dL}$; diabetes was defined as FBG $>125 \mathrm{mg} / \mathrm{dL}$ or PBG $>200 \mathrm{mg} / \mathrm{dL}$

In the instances where FBG was not available, diagnosis was based on PBG $(n=23)$
Given that there is evidence of $\mathrm{HbA}_{1 \mathrm{c}}$ levels being associated with both genetic factors $[11,27,28]$ and geographical settings [23] further investigation of $\mathrm{HbA}_{1 \mathrm{c}^{-}}$ FBG relationship in rural mountainous regions are required.

In contrast to the diagnosis of diabetes, $49 \%$ of study subjects who were diagnosed with pre-diabetes based on $\mathrm{HbA}_{1 \mathrm{c}}$ were classified as normal by measurement of FBG/PBG. Our findings are consistent with those of two recent studies which indicate considerable proportions of individuals who are prediabetic based on $\mathrm{HbA}_{1 \mathrm{c}}$ criteria have normal FBG results [24, 25]. However, others found that smaller proportions of pre-diabetics were identified by $\mathrm{HbA}_{1 \mathrm{c}}$ than glucose-based methods $[26,29]$. The divergence is unlikely to reflect device measurement errors, given the evidence that the point-of-care device used in our study has comparable performance to a laboratory based $\mathrm{HbA}_{1 \mathrm{c}}$ test $[30,31]$. Despite the fact that FBG and OGTT have both been widely used as the gold standards for diagnosing diabetes, there is still no uniform definition of pre-diabetes [32-35]. Marked discordance between pre-diabetes by $\mathrm{HbA}_{1 \mathrm{c}}$ and FBG/ PBG criteria in the present study therefore does not necessarily imply false positives. In fact, there is some evidence that $\mathrm{HbA}_{1 \mathrm{c}}$ and glucose-based diagnoses identify different populations within the hyperglycemic category [27, 29]. Both tests may offer uniquely important prognostic information.

The presence of a large proportion of individuals diagnosed as having pre-diabetes based on $\mathrm{HbA}_{1 \mathrm{c}}$ but with normal glucose-based results may have important prognostic implications. $\mathrm{HbA}_{1 \mathrm{c}}$ 's ability to predict major clinical complications such as cardiovascular disease is of major prognostic significance [36-38]. For example, $\mathrm{HbA}_{1 \mathrm{c}}$ levels were able to predict lipid profile, a key determinant of cardiovascular heart disease [37, 38]. Indeed, in a community-based study of non-diabetic, middle-aged adults in four U.S. communities, Selvin and colleagues observed that elevated $\mathrm{HbA}_{1 \mathrm{c}}(\geq 6 \%)$ was strongly associated with the risks of cardiovascular disease, all-cause mortality and ischemic stroke [38]. The associations remained strong and significant after adjusting for baseline FBG levels. Moreover, in individuals with stable coronary artery disease, $\mathrm{HbA}_{1 \mathrm{c}}$ values of $6.3 \%$ or greater were linked with adverse cardiovascular outcomes [36]. There is also evidence that reducing $\mathrm{HbA}_{1 \mathrm{c}}$ by $0.2 \%$ can lead to a $10 \%$ reduction in risk of mortality within 12 months [37]. Whether the increased risk of cardiovascular diseases associated with elevated $\mathrm{HbA}_{1 \mathrm{c}}$ is due to pre-diabetic conditions or the subsequent development of diabetes remains unclear $[39,40]$. However, the additional clinical information provided by a measurement of $\mathrm{HbA}_{1 \mathrm{c}}$ in the pre-diabetic range may 
render $\mathrm{HbA}_{1 \mathrm{c}}$ a more cost-effective option than FBG or OGTT, particularly in areas where comprehensive medical tests are less accessible and populations are more predisposed to cardiovascular diseases. Further research on this subject should be pursued in order that this additional prognostic benefit can be fully realized.

Another possible prognostic implication of prediabetes diagnosed by $\mathrm{HbA}_{1 \mathrm{c}}$ but not FBG/PBG lies in the prediction of progression to diabetes. In a systematic review of studies investigating the performance of $\mathrm{HbA}_{1 \mathrm{c}}$ in predicting progression to diabetes among adults aged 18 years and over, Zhang and colleagues observed that $\mathrm{HbA}_{1 \mathrm{c}} \geq 6.0 \%$ was associated with a very high risk of subsequent development of diabetes [41]. Pre-diabetes identified by fasting glucose and oral glucose tolerance tests, on the contrary, had limited ability to predict progression to diabetes [42]. On the other hand, others found similar rates of progression to diabetes in those identified as pre-diabetic by a single FPG test compared to a $\mathrm{HbA}_{1 \mathrm{c}}$ test $[43,44]$. Regardless, our current findings indicate that the prevalence of pre-diabetes in rural Garhwal is much higher than the national rural prevalence [4]. Given that timely lifestyle changes can be effective in preventing or delaying progression to diabetes [33], the advantages of using $\mathrm{HbA}_{1 \mathrm{c}}$ for mass screening of pre-diabetes in low-income rural areas may outweigh its disadvantages in the long run.

\section{Association with hemoglobin}

Consumptive anemia can confound the relationship between $\mathrm{HbA}_{1 \mathrm{c}}$ level and glycemic control $[14,45]$. Thus, it could potentially account for the observed difference in diagnoses of pre-diabetes by $\mathrm{HbA}_{1 \mathrm{c}}$ and FBG. However, we found that both the pattern and magnitude of differences in the proportions of pre-diabetes and diabetes diagnosed by $\mathrm{HbA}_{1 \mathrm{c}}$ compared with FBG/PBG, were independent of anemia status. There is prior evidence of substantial changes in $\mathrm{HbA}_{1 \mathrm{c}}$ levels in the presence of anemia $[14,15]$. In a recent systematic review of the effects of anemia and abnormalities of erythrocyte indices on $\mathrm{HbA}_{1 \mathrm{c}}$, the authors suggested that iron deficiency, and particularly iron deficiency anemia, may lead to an increase in $\mathrm{HbA}_{1 \mathrm{c}}$ [14]. In addition, relatively larger divergence was found between diagnoses of prediabetes and diabetes based on $\mathrm{HbA}_{1 \mathrm{c}}$ and OGTT, in a subgroup of young anemic adults who were deficient in iron, B12 and folic acid, when compared to a reference group [15]. The association between $\mathrm{HbA}_{1 \mathrm{c}}$ and hemoglobin concentration was also found to vary according to the forms of anemia. While iron deficiency anemia was associated with elevated $\mathrm{HbA}_{1 \mathrm{c}}$ [15], some forms of anemia were found to be linked with diminished $\mathrm{HbA}_{1 \mathrm{c}}$ level. A typical example is hemolytic anemia, in which the lifespan of erythrocytes is shortened, causing a drop in $\mathrm{HbA}_{1 \mathrm{c}}$ [14]. Other conditions which may decrease levels of $\mathrm{HbA}_{1 \mathrm{c}}$ include acute hemorrhage and hemoglobinopathies [46]. However, so far there is no consistent evidence regarding the influence of anemia and hemolytic disorders on $\mathrm{HbA}_{1 \mathrm{c}}$.

\section{Limitations}

Because of the difference in timing between $\mathrm{HbA}_{1 \mathrm{c}}$ and FBG tests, caution should be applied in the interpretation of these data. Participants were told their level of $\mathrm{HbA}_{1 \mathrm{c}}$ immediately after the test. Thus, some of the disparity between diagnosis of pre-diabetes by $\mathrm{HbA}_{1 \mathrm{c}}$ and FBG/PBG may be due to altered behavior between the two time points. However, lifestyle changes, if any, were unlikely to have contributed to the large disparity, given the minor differences in weight, body mass index and waist-hip ratio between time 1 and time 2. Furthermore, because we did not follow-up people who were categorized as having a normal $\mathrm{HbA}_{1 \mathrm{c}}$ at baseline, we will have missed detecting anyone who was negative for diabetes and pre-diabetes at the first assessment, but who were then positive using the glucose-based definition. This may mean that the differences that we observed are overestimated. We also acknowledge that our conclusions may not be generalizable across the whole region of Tehri-Garhwal because only five villages were surveyed. However, our findings provide preliminary evidence for a particularly high prevalence of diabetes and poor glycemic control in the sub-Himalayan region. They therefore provide the impetus for larger studies, including sampling of participants in a manner that represents the wider population of the region, to fully characterize the prevalence of diabetes in mountainous areas of North India.

\section{Conclusions}

Our study is one of the few in which $\mathrm{HbA}_{1 \mathrm{c}}$ has been utilized to diagnose diabetes in the mountainous rural communities in North India. The remarkably high prevalence of diabetes and pre-diabetes indicates the need for more in-depth research, including identification of the underlying determinants of diabetes and prediabetes in this region. More region-specific studies are needed in North India, especially where poverty and ethnic diversity are more pronounced. In view of the marked disparity in diagnosis of pre-diabetes between $\mathrm{HbA}_{1 \mathrm{c}}$ and FBG, health-care professionals should be well-informed of the complex determinants of $\mathrm{HbA}_{1 \mathrm{c}}$ to maximize the benefits of the $\mathrm{HbA}_{1 \mathrm{c}}$ test. From a policy perspective, there is a pressing need for advocacy of effective, tailor-made public health initiatives to prevent and respond to this imminent diabetes crisis in the rural mountainous regions of North India. 


\section{Additional files}

Additional file 1 Table S1. Distribution of participants according to village. (DOCX $14 \mathrm{~kb}$ )

Additional file $\mathbf{2}$ Table S2. Age, anthropometric and biochemical characteristics of participants at baseline, according to diabetes status as measured by $\mathrm{HbA}_{1 \mathrm{c}}$. (DOCX $\left.18 \mathrm{~kb}\right)$

\section{Abbreviations}

ASHAs: Accredited Social Health Activists; BMl: Body mass index; FBG: Fasting blood glucose; $\mathrm{HbA}_{1 \mathrm{c}}$ : Glycosylated hemoglobin; OGTT: Oral glucose tolerance test; PBG: Post-prandial blood glucose

\section{Acknowledgements}

The authors would like to acknowledge the participation of the villagers in the region.

\section{Authors' contributions}

PA analysed and interpreted data, and drafted manuscript. NG contributed to the design and concept, interpreted the data, and reviewed and edited manuscript. RS (Rajesh) contributed to the study design and training of staff, reviewed and edited manuscript. RS (Rajkumari) contributed to the training of staff, reviewed and edited manuscript. RGE contributed to the design and methods, interpreted the data, and reviewed and edited manuscript. PS contributed to the training of staff, reviewed and edited manuscript. AGT developed the concept of the research, designed this study, interpreted the data, and reviewed and edited manuscript. All authors have read and approved the manuscript.

\section{Funding}

This research was supported by funding from Monash University. AGT was supported by a National Health \& Medical Research Council fellowship (grant no. 1042600). The funding bodies had no role in the design of the study, in collection, analysis, and interpretation of data, nor in writing the manuscript.

\section{Availability of data and materials}

The datasets generated and/or analysed during the current study are not publicly available because these are small communities and publication of such data would compromise anonymity. However, a limited dataset, without age and other potentially identifying information, is available from the corresponding author on reasonable request.

\section{Ethics approval and consent to participate}

Ethics approval was obtained from the Garhwal Community Development and Welfare Society. Written informed consent was obtained from each participant before any data were collected.

\section{Consent for publication}

Not applicable.

\section{Competing interests}

The authors declare that they have no competing interests.

\section{Author details}

${ }^{1}$ Nossal Institute for Global Health, University of Melbourne, Melbourne, Australia. ${ }^{2}$ Garhwal Community Development and Welfare Society, Mussoorie Road, Chamba, India. ${ }^{3}$ Cardiovascular Disease Program, Biomedicine Discovery Institute and Department of Physiology, Monash University, Melbourne, Victoria, Australia. ${ }^{4}$ Christian Medical College, Ludhiana, India. ${ }^{5}$ Department of Medicine, School of Clinical Sciences at Monash Health, Monash University, Clayton, Victoria 3800, Australia.

\section{Received: 5 February 2019 Accepted: 17 June 2019}

\section{Published online: 24 June 2019}

\section{References}

1. Roglic G, Unwin N. Mortality attributable to diabetes: estimates for the year 2010. Diabetes Res Clin Pract. 2010;87:15-9.
2. Wild S, Roglic G, Green A, Sicree R, King H. Global prevalence of diabetes: estimates for the year 2000 and projections for 2030. Diabetes Care. 2004; 27:1047-53

3. Misra P, Upadhyay RP, Misra A, Anand K. A review of the epidemiology of diabetes in rural India. Diabetes Res Clin Pract. 2011;92:303-11.

4. Anjana RM, Deepa M, Pradeepa R, Mahanta J, Narain K, Das HK, et al. Prevalence of diabetes and prediabetes in 15 states of India: results from the ICMR-INDIAB population-based cross-sectional study. Lancet Diabetes Endocrinol. 2017:5:585-96.

5. Kumar PR, Bhansali A, Ravikiran M, Bhansali S, Dutta P, Thakur JS, et al. Utility of glycated hemoglobin in diagnosing type 2 diabetes mellitus: a community-based study. J Clin Endocrinol Metab. 2010;95:2832-5.

6. Mohan V, Deepa M, Deepa R, Shanthirani CS, Faroog S, Ganesan A, et al. Secular trends in the prevalence of diabetes and impaired glucose tolerance in urban South India--the Chennai Urban Rural Epidemiology Study (CURES-17). Diabetologia. 2006;49:1175-8.

7. Ramachandran A, Snehalatha C, Kapur A, Vijay V, Mohan V, Das AK, et al. High prevalence of diabetes and impaired glucose tolerance in India: National Urban Diabetes Survey. Diabetologia. 2001:44:1094-101.

8. Ravikumar P, Bhansali A, Ravikiran M, Bhansali S, Walia R, Shanmugasundar $\mathrm{G}$, et al. Prevalence and risk factors of diabetes in a community-based study in North India: the Chandigarh Urban Diabetes Study (CUDS). Diabetes Metab. 2011;37:216-21.

9. American Diabetes Association. Diagnosis and classification of diabetes mellitus. Diabetes Care. 2010;33(Suppl 1):S62-9.

10. Florkowski C. HbA1c as a diagnostic test for diabetes mellitus-reviewing the evidence. Clin Biochem Rev. 2013;34(2):75-83.

11. Bennett CM, Guo M, Dharmage SC. HbA (1c) as a screening tool for detection of type 2 diabetes: a systematic review. Diabet Med. 2007;24:333-43.

12. Sherwani SI, Khan HA, Ekhzaimy A, Masood A, Sakharkar MK. Significance of $\mathrm{HbA1c}$ test in diagnosis and prognosis of diabetic patients. Biomark Insights. 2016;11:95-104.

13. Sacks DB. A1c versus glucose testing: a comparison. Diabetes Care. 2011;34: 518-23.

14. English E, Idris I, Smith G, Dhatariya K, Kilpatrick ES, John WG. The effect of anaemia and abnormalities of erythrocyte indices on $\mathrm{HbA}_{1 c}$ analysis: a systematic review. Diabetologia. 2015;58:1409-21.

15. Hardikar PS, Joshi SM, Bhat DS, Raut DA, Katre PA, Lubree HG, et al. Spuriously high prevalence of prediabetes diagnosed by HbA (1c) in young Indians partly explained by hematological factors and iron deficiency anemia. Diabetes Care. 2012;35(4):797-802.

16. Malhotra $P$, Kumari $S$, Kumar $R$, Varma S. Prevalence of anemia in adult rural population of North India. J Assoc Physicians India. 2004;52:18-20.

17. Kassebaum NJ, on behalf of the GBD 2013 Anemia Collaborators. The global burden of anemia. Hematol Oncol Clin North Am. 2016;30:247-308.

18. World Health Organization. Hemoglobin concentrations for the diagnosis of anemia and assessment of severity: WHO/NMH/NHD/MNM/11.1; 2011.

19. Jayawardena R, Ranasinghe P, Byrne NM, Soares MJ, Katulanda P, Hills AP. Prevalence and trends of the diabetes epidemic in South Asia: a systematic review and meta-analysis. BMC Public Health. 2012;12:380.

20. Du TT, Yin P, Zhang JH, Zhang D, Shi W, Yu XF. Comparison of the performance of $\mathrm{HbA} 1 \mathrm{c}$ and fasting plasma glucose in identifying dysglycaemic status in Chinese high-risk subjects. Clin Exp Pharmacol Physiol. 2013;40:63-8.

21. Radhakrishna P, Vinod KV, Sujiv A, Swaminathan RP. Comparison of Hemoglobin A1c with fasting and 2-h plasma glucose tests for diagnosis of diabetes and prediabetes among high-risk South Indians. Indian J Endocrinol Metab. 2018;22(1):50-6.

22. Araneta MRG, Grandinetti A, Chang HK. A1C and diabetes diagnosis among Filipino-Americans, Japanese-Americans, and native Hawaiians. Diabetes Care. 2010;33:2626-8.

23. Bazo-Alvarez JC, Quispe R, Pillay TD, Bernabé-Ortiz A, Smeeth L, Checkley W, et al. Glycated haemoglobin ( $\mathrm{HbA} 1 \mathrm{c})$ and fasting plasma glucose relationships in sea-level and high-altitude settings. Diabet Med. 2017;34:804-12.

24. Ho-Pham LT, Nguyen UDT, Tran TX, Nguyen TV. Discordance in the diagnosis of diabetes: comparison between $\mathrm{HbA} 1 \mathrm{C}$ and fasting plasma glucose. PLoS One. 2017:12:e0182192.

25. Mayega RW, Guwatudde D, Makumbi FE, Nakwagala FN, Peterson S, Tomson $\mathrm{G}$, et al. Comparison of fasting plasma glucose and haemoglobin A1c point-of-care tests in screening for diabetes and abnormal glucose regulation in a rural low income setting. Diabetes Res Clin Pract. 2014;104:112-20. 
26. Pinelli NR, Jantz AS, Martin ET, Jaber LA. Sensitivity and specificity of glycated hemoglobin as a diagnostic test for diabetes and prediabetes in Arabs. J Clin Endocrinol Metab. 2011;96:E1680-3.

27. Herman WH, Cohen RM. Racial and ethnic differences in the relationship between $\mathrm{HbA1C}$ and blood glucose: implications for the diagnosis of diabetes. J Clin Endocrinol Metab. 2012;97:1067-72.

28. Venkataraman K, Kao SL, Thai AC, Salim A, Lee JJ, Heng D, et al. Ethnicity modifies the relation between fasting plasma glucose and $\mathrm{HbA} 1 \mathrm{C}$ in Indians, Malays and Chinese. Diabet Med. 2012;29:911-7.

29. Mann DM, Carson AP, Shimbo D, Fonseca V, Fox CS, Muntner P. Impact of A1c screening criterion on the diagnosis of pre-diabetes among U.S. adults. Diabetes Care. 2010;33:2190-5.

30. Hirst JA, McLellan JH, Price CP, English E, Feakins BG, Stevens RJ, et al. Performance of point-of-care HbA1c test devices: implications for use in clinical practice-a systematic review and meta-analysis. Clin Chem Lab Med. 2017:55:167-80

31. Lenters-Westra E, Slingerland RJ. Six of eight hemoglobin A1c point-of-care instruments do not meet the general accepted analytical performance criteria. Clin Chem. 2010;56:44-52.

32. Warren B, Pankow JS, Matsushita K, Punjabi NM, Daya NR, Grams M, et al. Comparative prognostic performance of definitions of prediabetes: a prospective cohort analysis of the Atherosclerosis Risk In Communities (ARIC) study. Lancet Diabetes Endocrinol. 2017;5:34-42.

33. Bansal N. Prediabetes diagnosis and treatment: a review. World J Diabetes. 2015;6:296.

34. Barry E, Roberts S, Oke J, Vijayaraghavan S, Normansell R, Greenhalgh T. Efficacy and effectiveness of screen and treat policies in prevention of type 2 diabetes: systematic review and meta-analysis of screening tests and interventions. BMJ. 2017;356:i6538.

35. Misra S. A flawed reference in assessing diagnostic accuracy leads to erroneous conclusions. BMJ. 2017;356.

36. Hong L-F, Li X-L, Guo Y-L, Luo S-H, Zhu C-G, Qing P, et al. Glycosylated hemoglobin $\mathrm{A} 1 \mathrm{C}$ as a marker predicting the severity of coronary artery disease and early outcome in patients with stable angina. Lipids Health Dis. 2014;13:89.

37. Khaw K-T, Wareham N, Luben R, Bingham S, Oakes S, Welch A, et al. Glycated haemoglobin, diabetes, and mortality in men in Norfolk cohort of European Prospective Investigation of Cancer and nutrition (EPIC-Norfolk). BMJ. 2001;322:15.

38. Selvin E, Steffes MW, Zhu H, Matsushita K, Wagenknecht L, Pankow J, et al. Glycated hemoglobin, diabetes, and cardiovascular risk in nondiabetic adults. N Engl J Med. 2010;362:800-11.

39. Sarwar N, Gao P, Seshasai S, Gobin R, Kaptoge S, Di Angelantonio E, et al. Diabetes mellitus, fasting blood glucose concentration, and risk of vascular disease: a collaborative meta-analysis of 102 prospective studies. Lancet. 2010;375:2215-22

40. Seshasai SRK, Kaptoge S, Thompson A, Di Angelantonio E, Gao P, Sarwar N, et al. Diabetes mellitus, fasting glucose, and risk of cause-specific death. N Engl J Med. 2011;364:829-41.

41. Zhang X, Gregg EW, Williamson DF, Barker LE, Thomas W, Bullard KM, et al. A1c level and future risk of diabetes: a systematic review. Diabetes Care. 2010;33:1665-73.

42. Genuth S, Kahn R. A step backward —or is it forward? Diabetes Care. 2008; 31:1093-6.

43. Gerstein H, Pogue J, Mann J, Lonn E, Dagenais G, McQueen M, et al. The relationship between dysglycaemia and cardiovascular and renal risk in diabetic and non-diabetic participants in the HOPE study: a prospective epidemiological analysis. Diabetologia. 2005;48:1749-55.

44. Morris DH, Khunti K, Achana F, Srinivasan B, Gray LJ, Davies MJ, et al. Progression rates from $\mathrm{HbA1c} 6.0-6.4 \%$ and other prediabetes definitions to type 2 diabetes: a meta-analysis. Diabetologia. 2013:56:1489-93.

45. Ford ES, Cowie CC, Li C, Handelsman Y, Bloomgarden ZT. Iron-deficiency anemia, non-iron-deficiency anemia and $\mathrm{HbAlC}$ among adults in the US. J Diabetes. 2011;3:67-73.

46. Gallagher EJ, Le Roith D, Bloomgarden Z. Review of hemoglobin a (1c) in the management of diabetes. J Diabetes. 2009;1:9-17.

\section{Publisher's Note}

Springer Nature remains neutral with regard to jurisdictional claims in published maps and institutional affiliations.

\section{Ready to submit your research? Choose BMC and benefit from:}

- fast, convenient online submission

- thorough peer review by experienced researchers in your field

- rapid publication on acceptance

- support for research data, including large and complex data types

- gold Open Access which fosters wider collaboration and increased citations

- maximum visibility for your research: over $100 \mathrm{M}$ website views per year

At $\mathrm{BMC}$, research is always in progress.

Learn more biomedcentral.com/submissions 